\title{
Controlling Rice Leaf Breaking Force by Temperature and Moisture Content to Reduce Breakage
}

\author{
Zhong Tang *(D, Yu Li, Ben Zhang, Meilin Wang and Yaoming Li \\ Key Laboratory of Modern Agricultural Equipment and Technology of Ministry of Education, \\ Jiangsu University, Zhenjiang 212013, Jiangsu, China; 18852857051@163.com (Y.L.); 18852865856@163.com (B.Z.); \\ wangmeilin1997@163.com (M.W.); ymli@ujs.edu.cn (Y.L.) \\ * Correspondence: tangzhong2012@126.com
}

Received: 29 February 2020; Accepted: 20 April 2020; Published: 29 April 2020

\begin{abstract}
Leaf fragments and grain mixture produced by rice threshing with a combine harvester seriously affects the subsequent grain cleaning efficiency. In this paper, rice leaf breaking force was tested at different temperatures and moisture contents to analyze the influence of temperature on the tensile properties of rice leaves. The overlapping regions of rice leaf breaking force and grain separation force at different temperatures were obtained. Based on the rice leaf breaking force, the effect of the temperature change on rice leaf with different moisture content was analyzed. The results showed that tensile strength of rice leaf decreased first, then increased and finally decreased from rice sheath to the top. The tensile breaking force of the leaf sheath was about $75 \mathrm{~N}$ ( $\mathrm{N}$ is Newton, $1 \mathrm{~N}=1 \mathrm{~kg} \cdot \mathrm{m} / \mathrm{s}^{2}$ ). The tensile fracture resistance of rice leaf was shown to weaken with the increase of temperature. The influence of the moisture content on the mechanical properties of rice leaf during the process of temperature change was small. At 30 to $35^{\circ} \mathrm{C}$, the blade was the strongest tensile fracture resistance, which was the lowest probability of fracture under the same stress condition. At this time, the rice grain separation force has the least coincidence with the rice leaf resistance to breakage. According to the breaking force of different blade layers, the number of blade layers has a significant linear relationship with its tensile limit. Therefore, the overall fracture resistance of the multilayer blade can be improved by controlling the temperature and moisture content.
\end{abstract}

Keywords: mature rice; rice threshing; grain separation; leaf fragment; tensile test

\section{Introduction}

Rice is an important food crop in the world [1,2]. Mechanized harvesting has become important in rice production, which has been an important guarantee for the world's rice harvesting [3,4]. With the increase of yield, the existing combine harvester threshing device often faces problems, such as high impurity content after threshing and very low grain cleaning efficiency $[5,6]$. High-yielding rice with abundant stalks and leaves is currently posing a huge challenge to existing threshing devices [7]. The mass ratio of grain to impurity in the mixture is about $3: 1$, but the volume ratio is 1:4. High impurity content after threshing makes it difficult to clean the subsequent grain [8]. The high impurity content after threshing by combine harvester was shown in Figure 1. The existing rice threshing device can achieve high grain threshing rate and low loss rate, but there is a problem of high impurity content after threshing.

Although there are many things that seriously affect the subsequent grain cleaning efficiency, high impurity content after threshing is the most important reason. In order to improve the cleaning efficiency of high impurity content, Craessaerts et al., (2010) developed a fuzzy control strategy by installing wind speed sensors and pressure sensors on the cleaning sieve, which could improve the detection and prediction of the cleaning loss status [9]. At the same time, Hiregoudar et al., 
(2011) developed a grain detection model for high impurity content cleaning process by artificial intelligence and neural networks [10]. The fuzzy logic control model for the combine harvester's cleaning system was a mature method and technique that can predict and control the cleaning loss rate [11]. High impurity content after threshing is an inevitable phenomenon. No matter how to improve the cleaning device, it is hard to solve the difficult of high impurity content after threshing. Thus, is there a way to reduce the broken rice leaves after threshing to improve the subsequent grain cleaning efficiency?

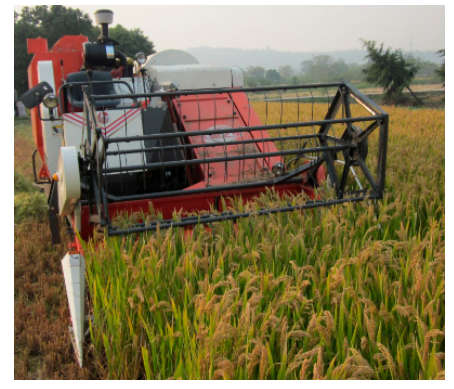

(a) Rice harvest in the field.

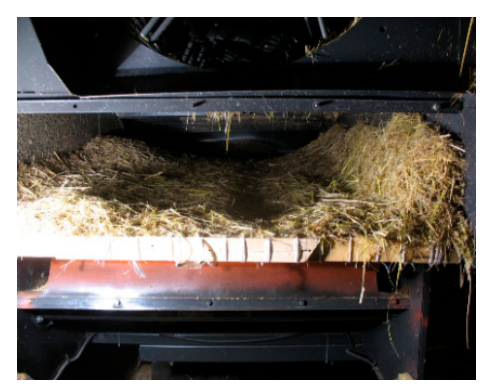

(b) Grain mixed with broken leaf

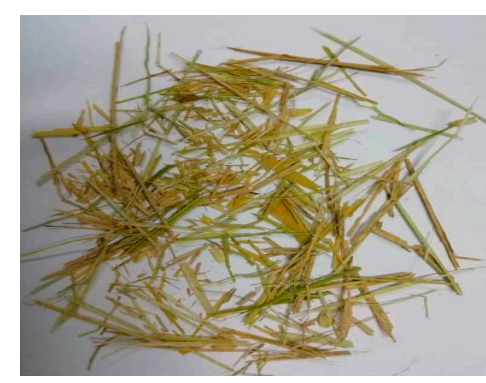

(c) Broken leaves after threshing

Figure 1. Natural rice and high impurity content after threshing by combine harvester.

After rice threshing, straw will produce stalks and rice leaves rupture. In order to investigate the morphological characteristics and changes of stems and leaves during threshing, Bart et al., (2014) tested the elastoplastic bending deformation wheat. The bending force process of wheat straw was simulated by the spring damping model of straw [12]. In exploring the causes of stalk breakage, Tom et al., (2016) used the Discrete Element Method to develop the force model at the wheat straw joint [13]. Based on the deformation mechanics joint force model, plastic characteristics of straw node were obtained. Geometric mechanical model of rice stems, leaf sheaths, leaves and ears, and the stiffness coefficients of rice stems and branches were developed by many scholars [14-16], such as Li et al., (2015), Zhang et al., (2020) and Ke et al., (2019). At present, the granule ruptures form, stalk deformation model and grain threshing characteristics in the threshing process are an important way to explore the reasons for the high impurity content after threshing. However, the existing reference have insufficient research on the stress state of rice leaves, the elastoplastic characteristics of rice leaves and the fracture conditions of rice leaves during rice threshing. Thus, the fracture mechanism of rice leaves during rice threshing process is still unclear.

During the rice harvesting process, it is necessary to consider not only the threshing rate, but also the threshing results such as the breaking rate and the impurity content $[17,18]$. Therefore, it is especially important to study the threshing force and its related factors. Effects of grain were simulated by EDM (discrete element method) to model the grain fracture and predict the damage characteristics by combining the proportional boundary finite element method and discrete element method [19]. Dai et al., (2019) studied the effects of the grain breakage rate at different speed flows in a threshing device and analyzed the motion trajectory of the grain by gas-solid coupling method [20]. Grain breakage rate and mechanical strength under different moisture contents were analyzed by many scholars [21,22], such as Zhao et al., (2019) and Tang et al., (2015). Tang et al., (2014) conducted a separation test on fresh and overripe rice heads at different moisture contents [23]. It was indicated that the separation force range of freshly mature rice grains ranged from $1.48 \mathrm{~N}$ ( $\mathrm{N}$ is Newton, $1 \mathrm{~N}=1 \mathrm{~kg} \cdot \mathrm{m} / \mathrm{s}^{2}$ ) to $2.29 \mathrm{~N}$ at different moisture contents, which are much bigger than that of overripe rice grains. There are different maturity levels for rice threshing. The proper harvest time would greatly improve yield and grain quality for rice threshing [24], thus, maturity is an important factor affecting the grain threshing performance of rice; the maturity index of rice is the moisture content. 
Therefore, based on the effect of the moisture content for the rice threshing process, we can get a better understanding of the laws and characteristics of rice leaf breakage during rice harvesting.

Moisture content is an important indicator of rice maturity. The change of moisture content will have certain influence on the physical properties of rice, but the moisture content itself is not easy to control artificially during the threshing process. However, the physical properties can be controlled by changing the moisture content and temperature. The effect of temperature on rice performance is still in its initial stage. Zhang et al., (2018) analyzed the temporal and spatial distribution of rice disasters caused by heat damage. It was indicated that $38.9^{\circ} \mathrm{C}, 39.5^{\circ} \mathrm{C}, 40.2{ }^{\circ} \mathrm{C}$ and $41.5^{\circ} \mathrm{C}$ are the thresholds for the mild, moderate, heavy and severe disasters of rice growth and development that can withstand high temperature and cause disasters [25]. It can be seen that temperature is an important factor that cannot be ignored for rice threshing performance. In order to study the effect of temperature on stems, Md-Sailm et al., (2017) used hot air and microwave drying methods to test the drying performance of flower stems at $40{ }^{\circ} \mathrm{C}, 50{ }^{\circ} \mathrm{C}$ and $60{ }^{\circ} \mathrm{C}$ [26]. It was indicated that microwave drying has good consistency and drying efficiency. Moisture content of rice could be controlled by temperature and then the difficulty of rice threshing is regulated. It can be seen that changing the temperature to a certain extent can improve the mechanical properties of rice. Therefore, to a certain extent, the rice breakage during threshing is reduced. However, the effect of the temperature on the mechanical properties of rice, especially the performance of rice leaf breakage, is not clear.

In this paper, the mechanical properties of rice leaves with different temperatures were studied and the effects of different temperatures on the mechanical properties of leaves and grains and their size were obtained. The relationship between the changes of different temperature, moisture content, leaves layers were analyzed, which could provide theoretical reference and experimental basis for the design of the rice threshing device.

\section{Material and Methods}

\subsection{Rice Leaves and Tensile Test Methods}

Rice is a cereal crop of Oryza (Oryza sativa L.). Rice is composed of stalks, leaves, ears and roots $[27,28]$. Broken leaf and grain are mixed together after rice threshing. In this paper, the rice leaves were hybrid japonica rice with good growth conditions. Rice variety was Zhendao growing in Jiangsu Province. Rice samples were all derived from artificially cut mature rice. Samples rice grown in the field are shown in Figure 2a. Samples rice leaves are shown in Figure 2b. Rice grains status are shown in Figure 2c.

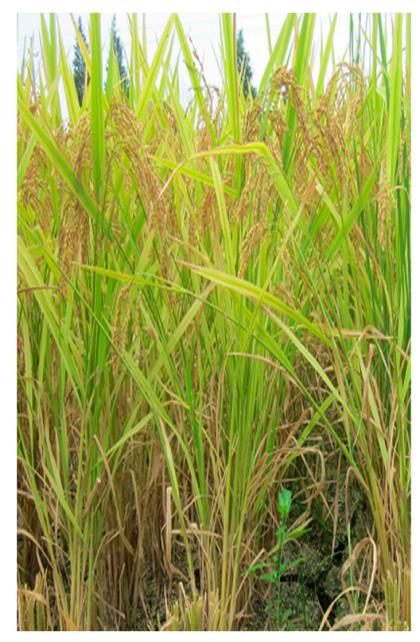

(a) Rice growth status

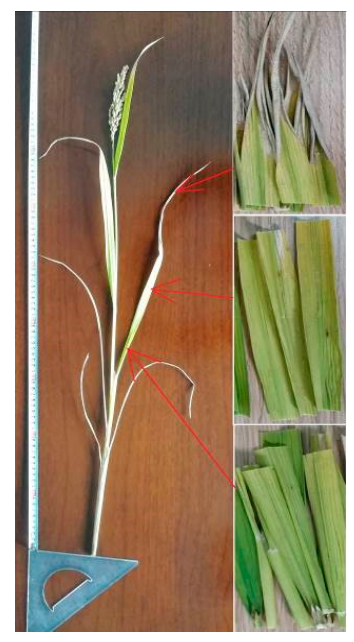

(b) Rice leaves status

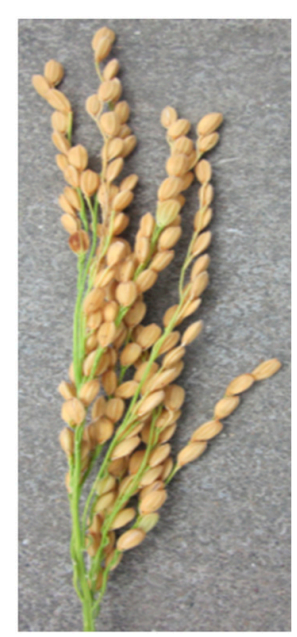

(c) Rice grain status

Figure 2. Status of rice plant and rice leaves and rice ear with grain. 
Because of the large individual differences in rice leaves, they needed to be screened before the experiment. The length, width and thickness were $60-65 \mathrm{~cm}, 2-2.5 \mathrm{~cm}$ and $0.5-0.8 \mathrm{~mm}$, respectively. The width and thickness of rice leaves varied from root to top, thus sample rice leaves needed to be grouped before the experiment. Rice grain separation force was tested from the rice ear.

The stress of the rice head in the threshing process is very complicated. Because it is surrounded by the stalk part, the force is also varied. Therefore, the simulation of the stress condition is complicated and not representative. The purpose of rice threshing is to achieve grain shedding, but it is not desirable to break other parts such as rice stems, leaves and platycodon. Therefore, the test of the separation force of a single grain is the key to this study to obtain the minimum force required for the separation of the grain from the ear. With this, the efficiency of rice threshing and the difficulty of cleaning due to the breakage of the blade portion can be better achieved. According to the actual stress condition of rice leaves during threshing, the mechanical properties of the leaves were comprehensively tested. The instrument used for the tensile tests of rice leaves was the Edgar 0824 push-pull testing machine (made by China Shenzhen Xindeya Precision Instrument Co., Ltd., Shenzhen, China), which was shown in Figure 3. The instrument's supporting software could display the pressure data in real time and could export the data for post processing. The specific instrument parameters were shown in Table 1.

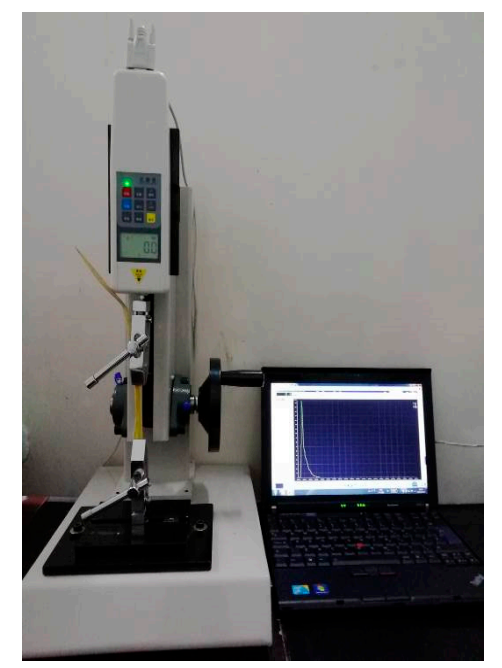

Figure 3. Edberg 0824 push-pull testing machine.

Table 1. Parameters of Edberg 0824 push-pull testing machine.

\begin{tabular}{cc}
\hline Model & HP-200 \\
\hline Test distance accuracy & $0.1 \mathrm{~mm}$ \\
Test force accuracy & $0.5 \%$ \\
sensors & Built-in pressure sensor \\
Test distance range & $0.1-180 \mathrm{~mm}$ \\
Power range & $+/-20 \mathrm{~kg}$ \\
PC interface & RS232C standard port or USB port \\
Operating temperature & $-20-70{ }^{\circ} \mathrm{C}$ \\
\hline
\end{tabular}

In this paper, the tensile properties of rice leaves were tested, including one end fixed with another end axial strength of rice leaf (abbreviation: two-point stretching), the fixed two ends with midpoint strength of rice leaf (abbreviation: three-point stretching), lateral tearing of rice leaf (abbreviation: transverse stretching) and tensile resistance when different numbers of leaf overlap (abbreviation: multi-layer blade stretching), which were shown in Figure 4a-d. A method of rice grain separation force from ear was shown in Figure 4e. 


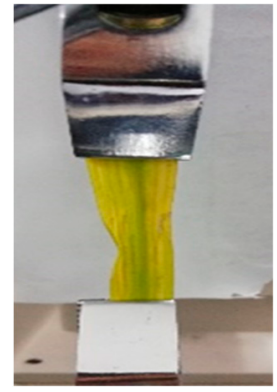

(a) Two-point stretching

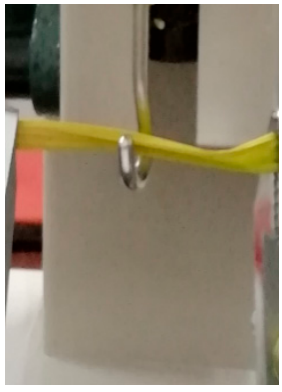

(b) Three-point stretching

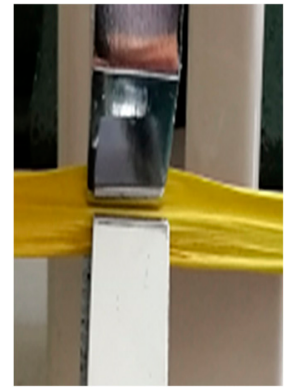

(c) Transverse stretching

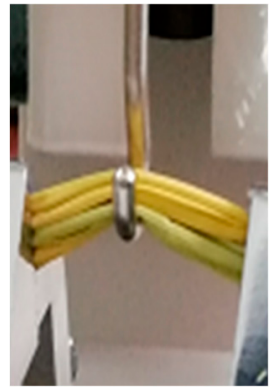

(d) Multi-layer blade stretching

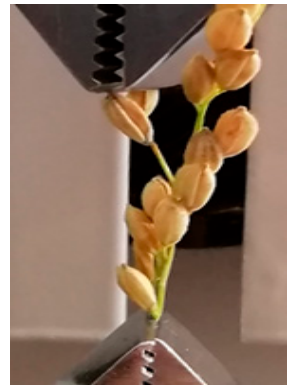

(e) Ear grain stretching

Figure 4. Tensile properties of rice leaves and grain.

Before the test, the fixture used to stretch the leaves or grain should be correctly installed, which should not be too tight during installation to prevent the internal stress from being too large to affect the test results. After the fixture was installed, the sensor was zeroed. The leaves or grain was installed on the fixture. The separation force test of the individual leaves or grain was carried out. Rice leaves used in experiment included the blade root, the middle, the top and the wrapped leaf points below the root. Samples rice leaves of different region were shown in Figure 5.

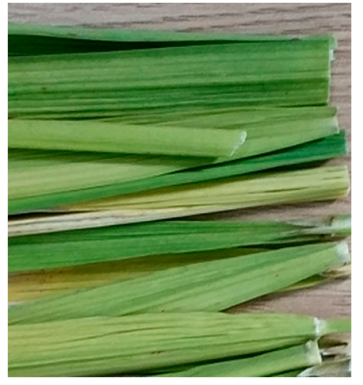

(a) Blade roots

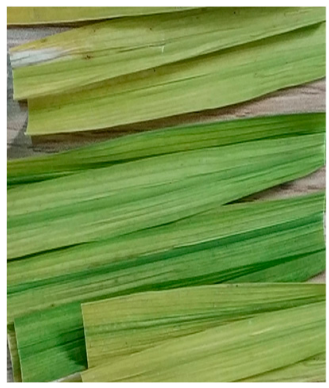

(b) Central blades

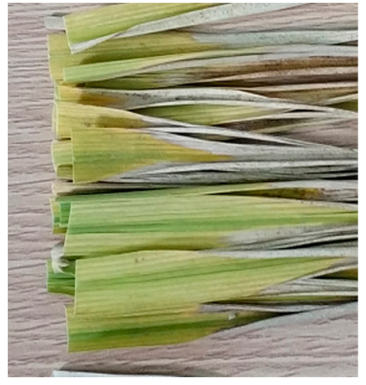

(c) Blade tops

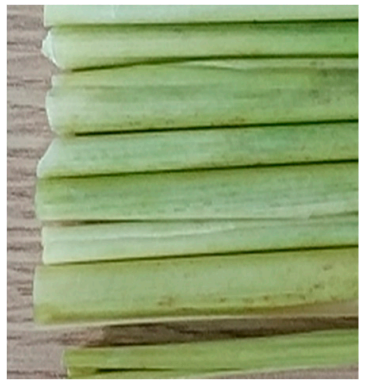

(d) Leaf sheath parts

Figure 5. Leaf samples used in this experiment.

The rice leaves used in the test were all fresh rice. Before the test, the rice was sheared and classified according to the root, middle and top. When selecting the test material, the physical characteristics of the same location including the length, width and thickness need to be consistent to ensure the reliability of the test results.

\subsection{Moisture Content and Temperature Control Methods}

In order to investigate the effect of changes in the moisture content of rice leaves on its mechanical properties, it is necessary to dry the rice leaves to reduce its moisture content. On this basis, tensile performance tests were performed on various parts of rice leaves under different moisture contents to study the effect of moisture contents on the mechanical properties of rice leaves [29]. In this paper, a Midea MM721NG1-PW microwave oven (made by Guangdong Midea Microwave Manufacturing Co., Ltd., Foshan City, China) was used to dry rice at different levels to achieve the purpose of reducing the moisture content of rice leaves. The specific test equipment and drying method is shown in Figure 6a. In order to investigate the effect of temperature on the mechanical properties of the blades, the existing test materials were used to test the tensile properties of the blades at different temperatures. The mechanical properties of rice leaves from $-10^{\circ} \mathrm{C}$ to $65^{\circ} \mathrm{C}$ were studied experimentally, and the temperature was increased by $5{ }^{\circ} \mathrm{C}$ each time. The test temperatures were $-10^{\circ} \mathrm{C},-5^{\circ} \mathrm{C}, 0{ }^{\circ} \mathrm{C}, \ldots, 65^{\circ} \mathrm{C}$. The specific test equipment and controlling method 
for temperature are shown in Figure 6b. A temperature box is an enclosed space. Moisture cannot be discharged during temperature control. The test equipment and method for measuring the surface temperature of rice leaves and grains are shown in Figure 6c. The parameter of the temperature measuring instrument UT301A (made by Unilead Technology (China) Co., Ltd., Shenyang City, China) infrared thermometer is that temperature range $-18-350{ }^{\circ} \mathrm{C}$, measurement accuracy is $1.8 \%$.

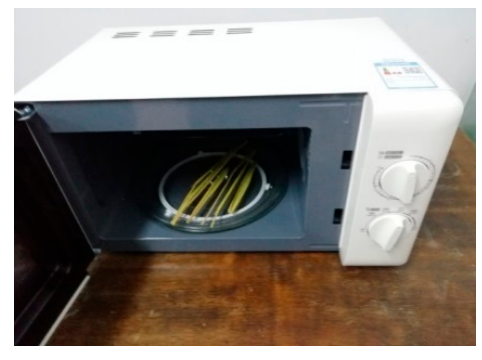

(a) Microwave oven for controlling moisture content

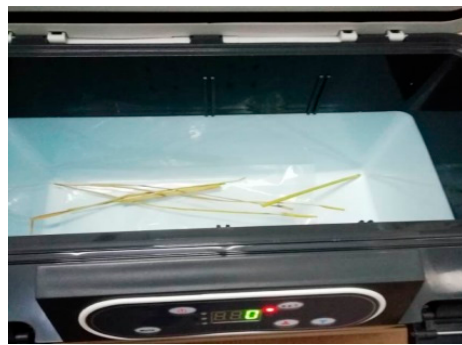

(b) Temperature box for controlling temperature

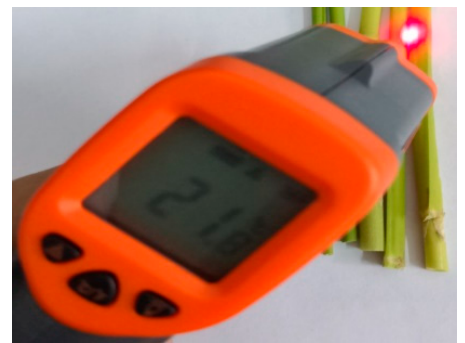

(c) Surface temperature testing instrument and method

Figure 6. Moisture content and temperature control equipment and methods.

During the tests, the microwave oven was adjusted to a low fire position, and the rice leaves were microwave-heated for 1 to $8 \mathrm{~min}$ to obtain different test samples with moisture content, which provided the basis for subsequent mechanical performance tests under different moisture content. In order to facilitate the comparison and analysis of the changes in the moisture content of rice leaves after drying, a weight test was performed on the moisture content of fresh rice. The instrument used for weighing was a model manufactured by China Wisdom Model RZ-2000 (made by Wuxi Changxie Electronics Co., Ltd., Wuxi City, China) electronic scale with a minimum accuracy of $0.01 \mathrm{~g}$. During the test, $43.70 \mathrm{~g}$ of rice leaves were taken for dehydration test. After the water was sufficiently dried, the remaining mass was measured to be $15.10 \mathrm{~g}$. According to the test results, the fresh rice has a moisture content of $65.45 \%$. The rice leaves under normal conditions were used as the initial reference data to compare and analyze the moisture content of rice leaves after different drying time.

The experimental materials were screened before the experiment, and the shape and size of the selected leaves needed to be consistent. The samples should be kept in the refrigerator for $1 \mathrm{~h}$ before classification, to ensure that the physical characteristics of each part tended to be consistent. The materials corresponding to each temperature were classified during the tests, taking $-10{ }^{\circ} \mathrm{C}$ as an example. The leaves were classified according to the root, middle and top of the blade, placed in an incubator, and the temperature was adjusted to $-10^{\circ} \mathrm{C}$. After the temperature was stable, the experimental materials were taken out. Since the ambient temperature differed greatly from the test temperature, the tests needed to be performed quickly and accurately. The test method at other temperatures was the same. After the end of the tests, the fractures of the same part of the blades at different temperatures were compared and analyzed.

\section{Results and Discussion}

\subsection{Rice Grain Separation Force}

Based on the individual rice grain separation tests, the damage was observed and photographed. The states of the grain after being pulled off were shown in Figure 7a. At the same time, the real-time data collected in the software is exported and processed, and the obtained grain separation test tensile force variation curves were shown in Figure $7 \mathrm{~b}$. 


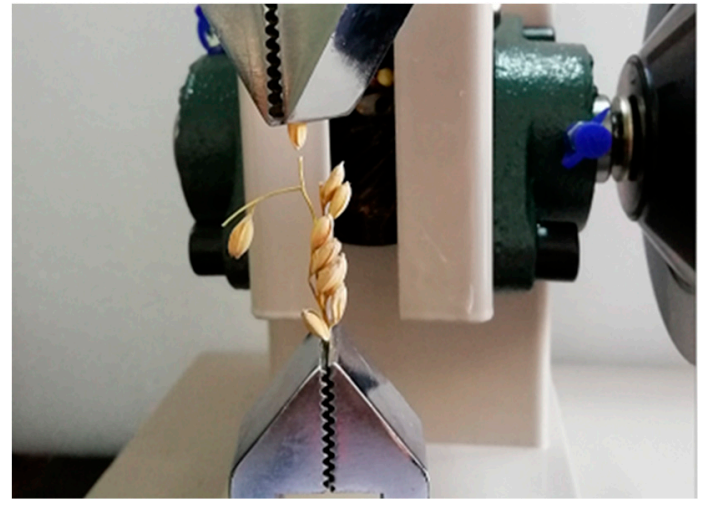

(a) Grain break state

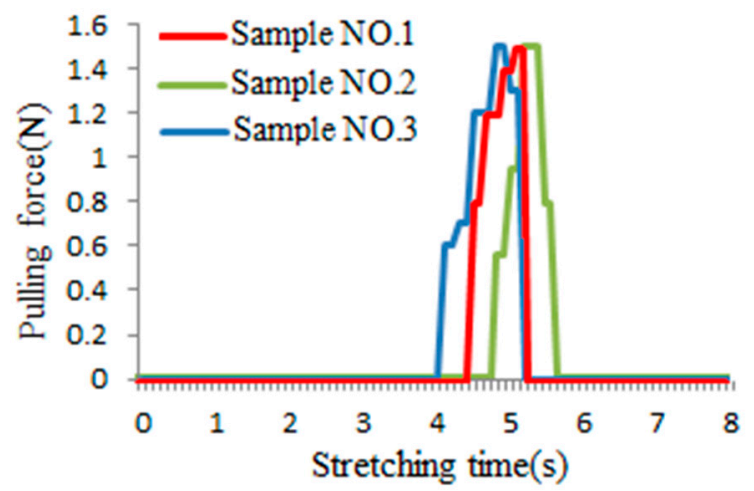

(b) Grain separation force curves

Figure 7. Rice grain break state and separation force curves.

As shown in Figure 7, the tensile strength of a single grain at room temperature was about $1.5 \mathrm{~N}$, and the variance was 0.11 . It can be seen that the force required for the separation of the grain at room temperature was very small, so that it is very easy to separate the individual grains, but it is not an ideal stress state due to the protection of the stems and the leaves around them. Tang et al., (2014) conducted a separation test on fresh and overripe rice heads at different moisture contents. The results showed that the separation force of freshly mature rice seeds ranged from $1.48 \mathrm{~N}$ to $2.29 \mathrm{~N}$ at different moisture contents [30,31]. The effect of temperature on the separation force of single grain is not obvious, although the rate of change of the separation force of the grain is relatively large during the temperature change. Since the force required for grain separation is very small, the overall variation is only within $1.5 \mathrm{~N}$, negligible from the point of view of the design of the threshing force of the threshing device. However, in order to reduce the completeness of the grain on the basis of reducing the impurity content of the broken leaves during the grain threshing process, and according to the test results, it was finally determined that the seed separation force is in the range of 1.2 to $2.2 \mathrm{~N}$ at different temperatures.

\subsection{Tensile Tests Results of Rice Leaves}

\subsubsection{Two-Point Tensile Under Different Moisture Contents and Temperature}

Eight groups of test materials were obtained after drying at different lengths in the microwave oven, which corresponded to rice leaf samples after $1 \mathrm{~min}, 2 \mathrm{~min}, \ldots, 8 \mathrm{~min}$ drying. A sample from each group of tests was taken; then, a weighing test was carried out after drying, to obtain the quality of the rice leaf samples after drying. The specific measurement results were shown in the Table 2. The moisture content of each sample after drying was calculated based on the mass and moisture content data of the rice leaf samples before drying.

Table 2. Effect of microwave oven heating on rice leaves on moisture content.

\begin{tabular}{ccccc}
\hline $\begin{array}{c}\text { Microwave } \\
\text { Heating Time/min }\end{array}$ & $\begin{array}{c}\text { Mass before Microwave } \\
\text { Heating/g }\end{array}$ & $\begin{array}{c}\text { Mass after Microwave } \\
\text { Heating/g }\end{array}$ & $\begin{array}{c}\text { Lost Moisture } \\
\text { Content/\% }\end{array}$ & $\begin{array}{c}\text { Moisture } \\
\text { Content\% }\end{array}$ \\
\hline 1 & 2.24 & 1.97 & 12.05 & 60.71 \\
2 & 2.68 & 1.84 & 31.34 & 49.68 \\
3 & 1.86 & 1.26 & 32.26 & 49.00 \\
4 & 2.63 & 1.62 & 38.40 & 43.91 \\
5 & 3.31 & 2.01 & 39.27 & 43.10 \\
6 & 3.10 & 1.72 & 44.52 & 37.73 \\
7 & 2.64 & 1.31 & 50.38 & 28.36 \\
8 & 1.96 & 0.92 & 53.06 & 26.39 \\
\hline
\end{tabular}


From the Table 2, the change curve and trend of the moisture content can be drawn in the whole process. The result is shown in the Figure 8a. After the two-point tensile tests were performed on rice samples with different drying durations, the fractured rice leaves were broken as shown in Figure $8 \mathrm{~b}$. The test results were analyzed to obtain the tensile change curves of various parts of rice leaves under different moisture contents. Taking the test results of the tensile force of the roots of the leaves when dried for $8 \mathrm{~min}$ as an example, the tensile change curves when the two points were stretched were shown in Figure 8c.

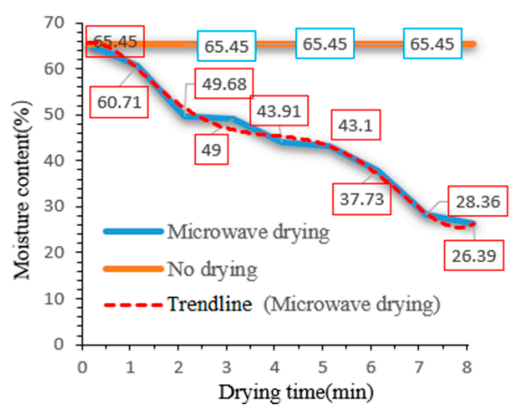

(a) Moisture content along time

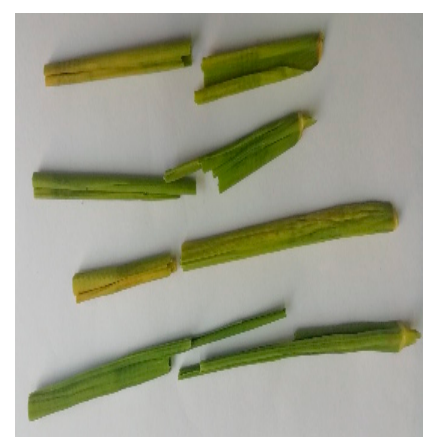

(b) Broken rice leaf

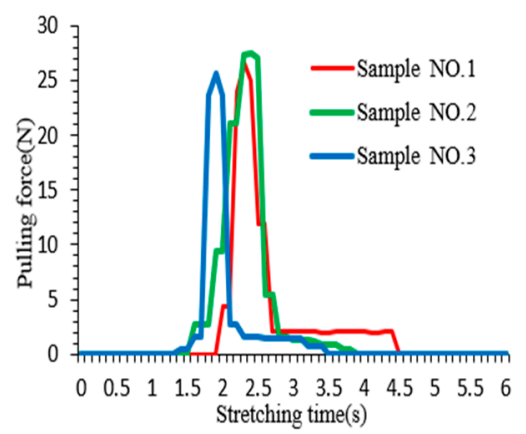

(c) Tensile after 8 min of drying

Figure 8. Effect of microwave drying time on moisture content.

From Table 2 and Figure 8, it can be seen that when it was heated for $8 \mathrm{~min}$, the moisture loss rate was $53.06 \%$, and the moisture content was only $26.39 \%$. The original moisture content of the rice sample was $65.45 \%$. When it was dried for $1 \mathrm{~min}$, it decreased by about $5 \%$, and after heating for $2 \mathrm{~min}$, it decreased by nearly $15 \%$. When it was heated for $3 \mathrm{~min}$ and $4 \mathrm{~min}$, the decrease was less. As the drying time increases, the moisture loss increases and the moisture content decreased.

The tensile performance data of rice leaves after the unreasonable drying time was analyzed and summarized to obtain the tensile performance data of rice leaves under different moisture content. The test data of the roots of the leaves are shown in Table 3.

Table 3. Tensile properties of blade root at two points under different moisture contents.

\begin{tabular}{cccccc}
\hline $\begin{array}{c}\text { Moisture } \\
\text { Content/\% }\end{array}$ & $\begin{array}{c}\text { Drying } \\
\text { Time/min }\end{array}$ & $\begin{array}{c}\text { Tensile Strength } \\
\text { (Sample NO. 1)/N }\end{array}$ & $\begin{array}{c}\text { Tensile Strength } \\
\text { (Sample NO. 2)/N }\end{array}$ & $\begin{array}{c}\text { Tensile Strength } \\
\text { (Sample NO. 3)/N }\end{array}$ & $\begin{array}{c}\text { Average/N } \\
\text { Variance }\end{array}$ \\
\hline 60.71 & $1 \mathrm{~min}$ & 32.0 & 33.3 & 32.6 & 32.63 \\
49.68 & $2 \mathrm{~min}$ & 31.7 & 32.2 & 30.9 & 31.60 \\
49.00 & $3 \mathrm{~min}$ & 31.5 & 31.3 & 30.8 & 31.20 \\
43.91 & $4 \mathrm{~min}$ & 30.6 & 31.2 & 29.5 & 30.43 \\
43.10 & $5 \mathrm{~min}$ & 30.3 & 30.9 & 29.3 & 30.17 \\
37.73 & $6 \mathrm{~min}$ & 28.7 & 27.8 & 27.5 & 0.50 \\
28.36 & $7 \mathrm{~min}$ & 28.2 & 27.7 & 27.3 & 0.44 \\
26.39 & $8 \mathrm{~min}$ & 26.6 & 27.3 & 25.7 & 27.40 \\
\hline
\end{tabular}

Abbreviations: $\mathrm{N}$ is Newton, $1 \mathrm{~N}=1 \mathrm{~kg} \cdot \mathrm{m} / \mathrm{s}^{2}$.

The data of tensile properties of rice roots under different drying time were analyzed and processed. The change curves with drying time and moisture content were obtained, and the results are shown in Figure $9 a, b$.

As can be seen in Figure 9, the corresponding data that the moisture content and tensile properties of rice leaves decreased with an increasing drying time. There was a certain linear relationship between tensile properties and drying time within a certain time, but it was not completely linear, and there was no obvious linear relationship between drying time and moisture content. With the decrease of moisture content, the tensile resistance of rice leaves gradually decreased, and the change rate showed a trend of increasing first and then decreasing. That is, the influence of the change in unit moisture 
content on its tensile properties increased first and then decreased. On the whole, it could be seen that the change in moisture content had a great impact on the tensile properties of rice. During the whole test, the moisture content of rice leaves decreased by about $40 \%$, which resulted in a reduction of the tensile properties of rice leaves by about $25 \%$.

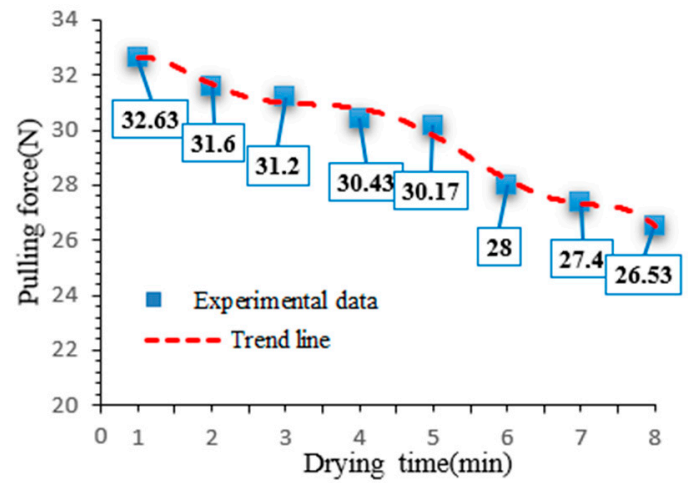

(a) Tensile performance with drying time

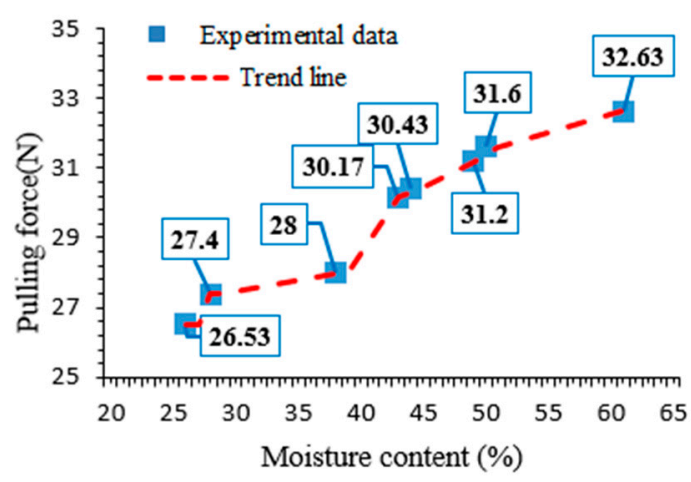

(b) Tensile performance with moisture content

Figure 9. Curve of leaf tensile performance with different drying time and moisture content.

The blades portion broken states of the middle fractures of the blades, the top fractures of the blades and the leaf sheath at the root of the blades were as shown in Figure 10a-c.

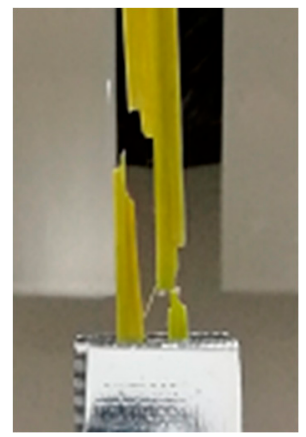

(a) Middle fractures of blades

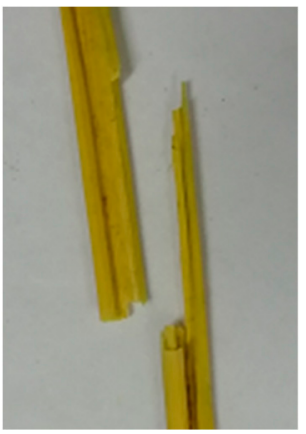

(b) Top fractures of blades

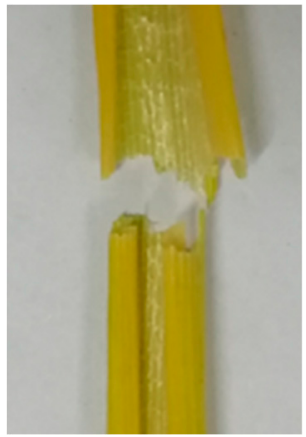

(c) Leaf sheath at blades root

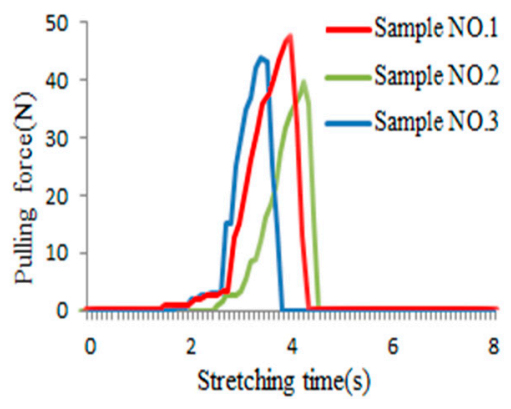

(d) Tensile force at normal temperature

Figure 10. Tensile fracture modes and tensile force curves of stretching blades.

It could be seen from the fracture state of the leaves that the leaves were similar to the rice stems and belong to the fiber structure. The physical properties of each location were different, thus, the location of the fracture was random. Besides the shapes of the fracture was not a straight line, but a line with uneven distribution. The test data was exported, and the tensile mechanical properties of each position at $20^{\circ} \mathrm{C}$ were obtained. Taking the middle of the blades as an example, the two-point stretching results at room temperature were shown in Figure 10d.

The stretching test data of rice leaves were processed and statistically analyzed. The main data of each part of the leaves are shown in Table 4.

Table 4. Main data of two-point stretching of blades at room temperature.

\begin{tabular}{ccccc}
\hline Main Indicators & $\begin{array}{c}\text { The Root of The } \\
\text { Blades }\end{array}$ & $\begin{array}{c}\text { The Middle of } \\
\text { The Blades }\end{array}$ & $\begin{array}{c}\text { The Top of The } \\
\text { Blades }\end{array}$ & $\begin{array}{c}\text { The Sheath of The } \\
\text { Blades }\end{array}$ \\
\hline Average/N & 32.34 & 43.33 & 7.36 & 82.52 \\
Variance & 1.56 & 3.85 & 4.22 & 4.23 \\
\hline
\end{tabular}


From the data of Figure 10 and Table 4, the root of the blade can withstand a tensile force of about $32 \mathrm{~N}$, and the test sample had a variance of 1.56. The tension in the middle of the blade can be about $43 \mathrm{~N}$, and the variance was 3.85. This was closely related to the shape and physical properties of the blade itself. It could be seen from Figure 2 that the thickness of the blade at different positions was not the same. The thickness at the root was thicker than the top of the blade, and the width tended to become wider and then narrow. Considering the differences in moisture during the growth of the leaves and the fact that the upper ends of the leaves were in the sun, there was a large difference in the moisture content of the same leaves at different locations. Therefore, from all aspects, the tensile strength of the top of rice leaves should be very small compared with the tensile properties of the roots. From the root to the middle of the blades to the top tensile properties, it could be seen that the tensile strength of the blades from the root to the top was much reduced. The top could withstand a tensile force of about $7 \mathrm{~N}$, and the root and middle tensile properties were approximately four to five times that of the top. After removing the sheath, the root of the blade was not the best tensile strength of its entire structure. The moisture content and thickness of the root of the blade were incomparable at other locations, but the middle part of the blade was the widest and the moisture content of the part was not much different from the root. Besides the effect of the thickness on its tensile properties was not as great as the effect of the width, so that the tensile properties in the middle of the blades were the best. Of course, not all blades are like this. Some blades may have little difference between the root and the middle in the width direction; however, the maximum tensile strength might still be in the root.

As can be seen from Table 4, the tensile properties of the various portions of the blade were not the same and varied greatly. The sheath had the strongest tensile strength and could withstand a tensile force of about $82 \mathrm{~N}$. This part was equivalent to the outermost protective skin of the stalk, thus, the mechanical properties of this position were the best. Therefore, it could protect the stem itself from being subjected to external force to a certain extent without serious damage, which was compatible with the self-protection of the plant itself and the natural law. It could be seen that when the force of the blades during the threshing process was two-point stretching, the threshing force exceeded the tensile limit, and thus most of the fracture occurred after threshing.

\subsubsection{Three-Point Stretching of the Blades at Normal Temperature}

Tensile fracture states of the blades root, the middle, the top fracture and the leaf sheath partial fracture of the blades root were as shown in Figure 11a-d.

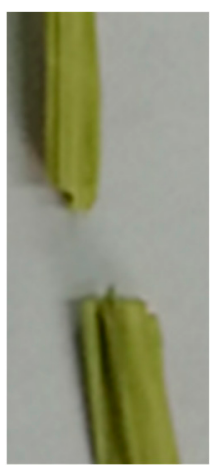

(a) Root of blades

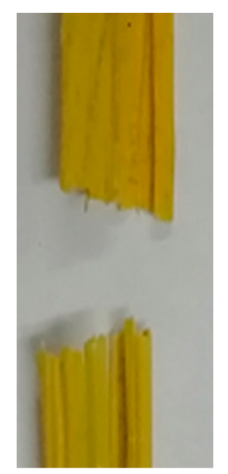

(b) Middle of blades

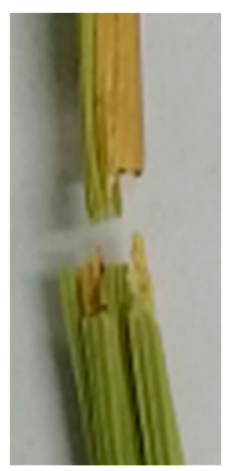

(c) Top of blades

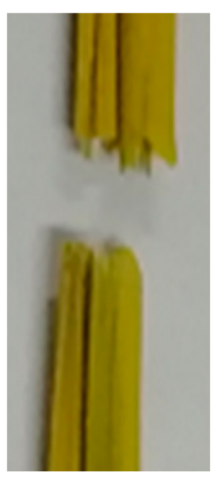

(d) Leaf of sheath root

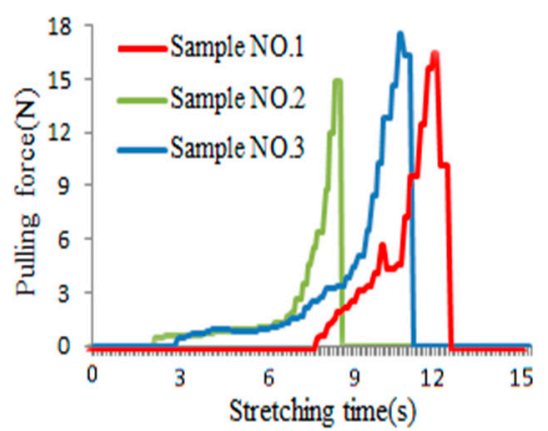

(e) Tensile force of blades at normal temperature

Figure 11. Tensile fracture states and tensile force curve of three-point stretching blades.

As can be seen in Figure 11a-d, the fracture position of the blades basically occurred at the tensioned position, and the shapes of the port had a large randomness. Since the blades were not only subjected to the pulling force of the three-point stretching but also subjected to a certain range of torque, the force states were relatively complicated to stretch at two points, resulting in a certain distortion of 
the port position unevenness. When the moisture content of the blade itself was high, its toughness was strong. Especially in the root and middle of the blades, it may break several times during the tensile fracture process. It belonged to the fiber structure, and the arrangement was exactly perpendicular to the direction of the force. As a result, it caused breakage at different positions; the port was not a straight line but rather saw toothed or even further positions, because rice leaves are longitudinal fiber structures. The tests data was exported and processed to obtain the tensile mechanical properties of each position at $20^{\circ} \mathrm{C}$, which was shown in Figure 11e.

The stretching test data of rice leaves were processed and statistically analyzed. The main data of each part of the leaves were shown in Table 5.

Table 5. Main data of three-point stretching of the blades at normal temperature.

\begin{tabular}{ccccc}
\hline Main Indicators & $\begin{array}{c}\text { The Root of The } \\
\text { Blades }\end{array}$ & $\begin{array}{c}\text { The Middle of } \\
\text { The Blades }\end{array}$ & $\begin{array}{c}\text { The Top of The } \\
\text { Blades }\end{array}$ & $\begin{array}{c}\text { The Sheath of The } \\
\text { Blades }\end{array}$ \\
\hline Average/N & 17.27 & 11.32 & 7.32 & 38.62 \\
Variance & 2.25 & 3.54 & 2.33 & 4.23 \\
\hline
\end{tabular}

From the data of Figure 11 and Table 5, the ultimate tensile forces corresponding to the three-point stretching of the blade root and the blade top were $17.3 \mathrm{~N}$ and $7.3 \mathrm{~N}$, respectively, and the corresponding variances were 2.25 and 2.33, respectively. The force of three-point stretching was more common in the process of threshing. In most cases, the force of the blades was three-point stretching. It could be seen that the tension of the blades during threshing had completely exceeded its tensile limit, thus, it was all fragments and there were no complete blades after threshing. The test results showed that the tensile properties of the blades at the three-point stretching were significantly reduced compared to the two-point stretching at the same position of the blades. The tensile limit of the blades at the top of the two forces was not much different. The reason for this result may be that the blades were strongly squeezed in the middle part of the three-point stretching to cause the tissue to break. The two-point stretching was performed on a flat surface. Therefore, it was easier to pull off when stretching at three points relative to two-point stretching. For the top of the blades, considering that its own width was narrow and the structure was relatively fragile, the force required for breaking was small. Even if there was a deviation, it was not obvious. Due to the difference in physical properties between different test materials, the difference in strength between the two stress cases was small. In general, the blades were more likely to break when three-point stretching was applied.

\subsubsection{Tensile Mechanical Properties of Blades Transverse Tear}

Transverse fracture states of the blade states with partial rice leaves and complete rice leaves were as shown in Figure 12a,c. Based on the blade transverse tear test, the analysis and processing resulted in tensile force change curve when the blades were laterally pulled. Stretching force curve of blades transverse tear with partial rice leaves and complete rice leaves were as shown in Figure 12b,d.

As can be seen in Figure 12a,c, when the blades were laterally pulled, the shape of the fracture was relatively regular. The leaf veins are fibrous structures with a distinct texture in the longitudinal direction, so that when a certain position was torn, the filamentous structure along the blade continued to crack. The main reason for this phenomenon is that the mechanical properties between adjacent filamentous textures are weak. This test only showed the damage law of the blades being torn when the blades were subjected to the transverse tension alone. When it was subjected to both lateral and longitudinal stretching, the shape of the fracture may be offset. It differed from the shape of the fracture when subjected to lateral tension alone, but its general tear direction would break along the grain direction of the weak position of the blade.

As can be seen in Figure 12b,d, when the blades were laterally pulled, the maximum tensile force that could be withstood in the middle of the blades were about 1-3 N. The transverse tensile properties of the whole leaf were stronger than those of the partial leaves. However, the tensile limit differed 
greatly from the threshing force of the threshing cylinder on the blades, thus, the blades were prone to lateral tearing during the threshing process. It could be seen from Figure 1 that the leaves after threshing were mostly incompletely broken. The broken leaves had different degrees of tearing in the lateral direction, which was consistent with the results obtained by the tests.

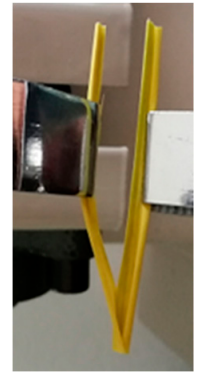

(a) Partial rice leaves

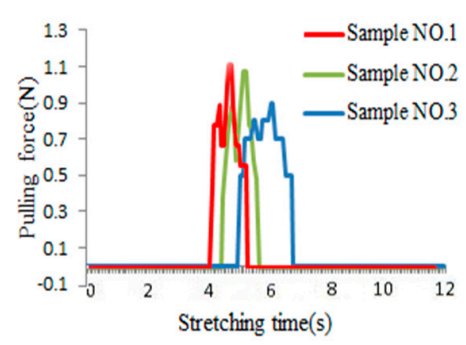

(b) Stretching force curve of partial rice leaves

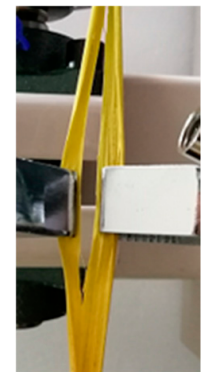

(c) Complete rice leaves

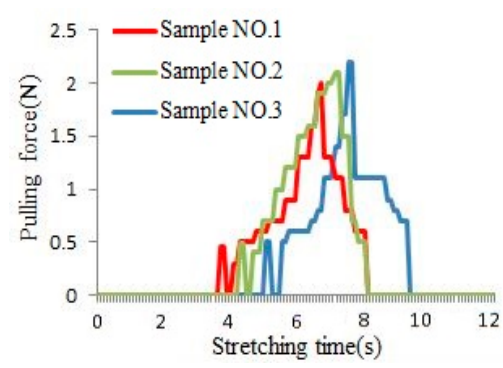

(d) Stretching force curve of complete rice leaves

Figure 12. Transverse fracture states and stretching force curve of blades transverse tear.

\subsection{Tensile Performance of Blades at Different Temperatures}

\subsubsection{Two-Point Stretching of Blades}

Due to the physical properties of the blade itself, even if the similarly selected blades were manually selected, the differences between the individuals still existed, which affected the mechanical properties of the blades at some time. The tensile properties of the blade roots at the lowest temperature and the highest temperature were shown in Table 6.

Table 6. Tensile properties of the blade root at the highest and lowest temperatures.

\begin{tabular}{cccccc}
\hline Temperature/ ${ }^{\circ} \mathbf{C}$ & $\begin{array}{c}\text { Tensile Strength } \\
\text { (Sample NO. 1)/N }\end{array}$ & $\begin{array}{c}\text { Tensile Strength } \\
\text { (Sample NO. 2)/N }\end{array}$ & $\begin{array}{c}\text { Tensile Strength } \\
\text { (Sample NO. 3)/N }\end{array}$ & Average/N & Variance \\
\hline-10 & 28.68 & 27.52 & 28.30 & 28.23 & 0.25 \\
65 & 29.30 & 29.67 & 29.13 & 29.37 & 0.39 \\
\hline
\end{tabular}

As can be seen in Table 6 , the tensile limit of the blade root at about $-10{ }^{\circ} \mathrm{C}$ was about $28 \mathrm{~N}$, and the variance was 0.25 . At $65^{\circ} \mathrm{C}$, the blade root could withstand a tensile limit of about $29 \mathrm{~N}$ and a variance of 0.39 . The tensile properties of the blades from the lowest and highest temperatures could not be seen to be different obviously, because the experimental materials themselves had certain physical properties. It was necessary to analyze the trend of the whole. Taking the root of the stalks as an example, the corresponding force at different temperatures can be matched with the temperature to obtain the curve. Two-point tensile ultimate force-temperature curve was shown in Figure 13.

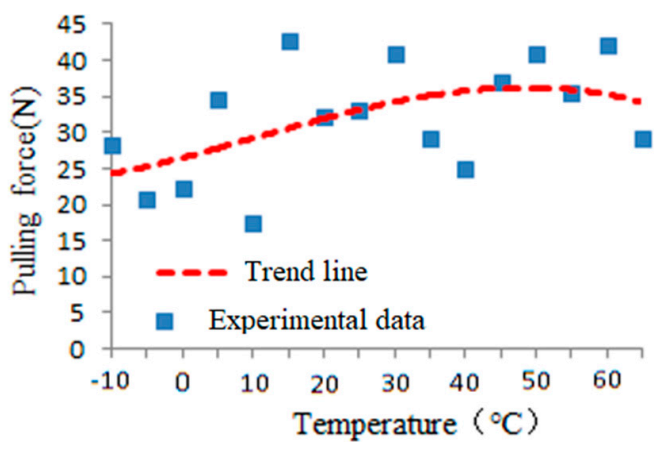

Figure 13. Two-point tensile ultimate force temperature curve. 
The specific data of two-point tensile test tensile strength of the blades at each temperature was shown in Table 7.

Table 7. Two-point tensile test tensile strength of the blades at each temperature.

\begin{tabular}{cccccc}
\hline Temperature $/{ }^{\circ} \mathbf{C}$ & $\begin{array}{c}\text { Average Tensile } \\
\text { Limit/N }\end{array}$ & Variance & Temperature/ ${ }^{\circ} \mathbf{C}$ & $\begin{array}{c}\text { Average Tensile } \\
\text { Limit } / \mathbf{N}\end{array}$ & Variance \\
\hline-10 & 28.23 & 0.25 & -5 & 20.89 & 0.36 \\
0 & 22.21 & 0.46 & 5 & 34.56 & 0.52 \\
10 & 17.53 & 1.48 & 15 & 42.83 & 1.44 \\
20 & 32.34 & 1.56 & 25 & 33.16 & 2.13 \\
30 & 41.00 & 1.33 & 35 & 29.32 & 0.65 \\
40 & 25.00 & 0.72 & 45 & 37.18 & 1.23 \\
50 & 40.81 & 1.35 & 55 & 35.43 & 1.72 \\
60 & 42.23 & 2.33 & 65 & 29.37 & 0.39 \\
\hline
\end{tabular}

As can be seen in Table 7, the blades had different tensile properties at different temperatures. The tensile properties of the blades from -10 to $65^{\circ} \mathrm{C}$ showed a tendency to increase and then weaken, and the blades had the weakest tensile performance at around $13{ }^{\circ} \mathrm{C}$. When the temperature was low, the blades had weak tensile properties, and its tensile properties were improved after the temperature increased. Due to the certain differences in the structure of the blade itself, there may be some deviation in the data. The general trend was that the tensile properties were poor when the temperature was low, and the tensile properties were improved within a certain range when the temperature was high. As the temperature increased, the physical properties of the blade itself may change due to the moisture content, which may result in weaker tensile properties. From the trend line obtained from the data, it could be seen that the tensile strength of the two-point stretching of the blades at high temperature was better than that at low temperature. Its tensile performance was best at around $35^{\circ} \mathrm{C}$. The reason why the specific factors changed the tensile properties with temperature changes remained to be further explored.

\subsubsection{Three-Point Stretching of Blades}

Due to the large number of test data, the tensile performance at the top of the blades at the lowest temperature and the highest temperature was Table 8.

Table 8. Tensile properties of the blade top at the highest and lowest temperatures.

\begin{tabular}{cccccc}
\hline Temperature/ ${ }^{\circ} \mathbf{C}$ & $\begin{array}{c}\text { Tensile Strength } \\
\text { (Sample NO. 1)/N }\end{array}$ & $\begin{array}{c}\text { Tensile Strength } \\
\text { (Sample NO. 2)/N }\end{array}$ & $\begin{array}{c}\text { Tensile Strength } \\
\text { (Sample NO. 3)/N }\end{array}$ & Average/N & Variance \\
\hline-10 & 3.19 & 3.43 & 3.64 & 3.42 & 0.34 \\
65 & 6.13 & 6.23 & 6.90 & 6.42 & 0.12 \\
\hline
\end{tabular}

As can be seen in Table 8, the tensile limit at the lowest temperature of $-10^{\circ} \mathrm{C}$ at the top of the blade was about $3.4 \mathrm{~N}$ and the variance was 0.34 . The maximum tensile force at a maximum temperature of $65^{\circ} \mathrm{C}$ was about $6.4 \mathrm{~N}$ with a variance of 0.12 . Although the results were different, the total number was small. Therefore, the tensile properties of various parts of the blades at different temperatures need to be analyzed. The tensile properties of the top of the blades at different temperatures were shown in Figure 14. Three-point tensile test blades tensile limit at different temperature was Table 9. 


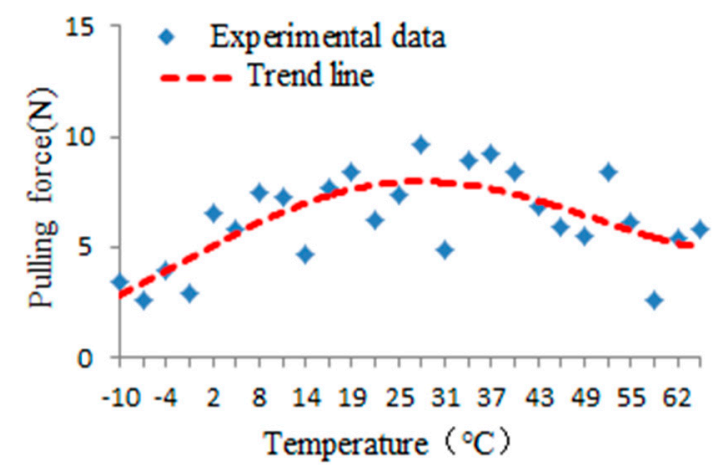

Figure 14. Three-point tensile ultimate force temperature curve.

Table 9. Three-point tensile test blades tensile limit at each temperature.

\begin{tabular}{cccccc}
\hline Temperature $/{ }^{\circ} \mathbf{C}$ & $\begin{array}{c}\text { Average Tensile } \\
\text { Limit/N }\end{array}$ & Variance & Temperature/ ${ }^{\circ} \mathbf{C}$ & $\begin{array}{c}\text { Average Tensile } \\
\text { Limit/N }\end{array}$ & Variance \\
\hline-10 & 3.42 & 0.34 & -7 & 2.65 & 0.23 \\
-4 & 3.93 & 0.28 & -1 & 2.94 & 0.26 \\
2 & 6.56 & 0.33 & 5 & 5.89 & 0.13 \\
8 & 7.54 & 0.29 & 11 & 7.35 & 0.36 \\
14 & 4.79 & 0.56 & 16 & 7.76 & 0.22 \\
19 & 8.49 & 0.39 & 22 & 6.22 & 0.45 \\
25 & 7.46 & 0.32 & 28 & 9.62 & 0.66 \\
31 & 4.94 & 0.36 & 34 & 8.94 & 0.22 \\
37 & 9.26 & 0.23 & 40 & 8.47 & 0.17 \\
43 & 6.86 & 0.11 & 46 & 5.96 & 0.26 \\
49 & 5.57 & 0.26 & 52 & 8.45 & 0.29 \\
55 & 6.18 & 0.57 & 58 & 2.66 & 0.36 \\
62 & 5.41 & 0.29 & 65 & 6.42 & 0.12 \\
\hline
\end{tabular}

As can be seen in Figure 14 and Table 9, it could be seen that the overall trend of the tensile properties of the blades was that as the temperature increased, its tensile properties became stronger first and then weaker. The tensile properties of the blades were weak at low temperature and high temperature, and the tensile properties were better at normal temperature. The trend analysis obtained from the experimental data showed that the blades had the best tensile performance at around $28^{\circ} \mathrm{C}$. However, as the temperature gradually increased, the physical properties of the blades became worse and worse. It may be that the moisture was lost due to the increase in temperature, and the performance of each part of the structure was weakened, resulting in a decrease in tensile properties. When the temperature of the blades was low, the mechanical properties were weak and the internal structure was brittle, thus, they were more likely to be broken when pulled. This test only gave a general trend. The tensile limit of rice leaves at different temperatures was also different due to the difference between different varieties and the characteristics of the objects. Considering that the three-point stretching was in the state of artificially simulated blade tension, the fixture also had a certain artificial deviation during installation, and the system also had a certain deviation during the experiment. Even if the same blade had a certain difference in tensile properties during tension, the quantitative data obtained from this part of the test was only a reference for the force-temperature relationship. Specific mathematical models and relationships need to be further explored, for which this experiment provided an important value reference.

\subsection{Moisture Content Law at Different Temperature}

During the test, the temperature was changed from $-10{ }^{\circ} \mathrm{C}$ to $60^{\circ} \mathrm{C}$, and each time changed by $5{ }^{\circ} \mathrm{C}$, with a total of 16 samples. The changed mass of each sample was compared with the mass before the sample was put in so as to obtain its relative water loss. The moisture content of each sample 
at different temperatures was obtained through calculation. The specific experimental results were shown in Table 10.

Table 10. Effect of incubator controlling rice leaves and grains on moisture content.

\begin{tabular}{ccccc}
\hline Temperature/ ${ }^{\mathbf{C}} \mathbf{C}$ & $\begin{array}{c}\text { Mass before Temperature } \\
\text { Adjustment/g }\end{array}$ & $\begin{array}{c}\text { Mass after Temperature } \\
\text { Adjustment/g }\end{array}$ & $\begin{array}{c}\text { Reduction in Moisture } \\
\text { Content/\% }\end{array}$ & $\begin{array}{c}\text { Moisture } \\
\text { Content/\% }\end{array}$ \\
\hline 65 & 2.96 & 2.81 & 5.07 & 63.61 \\
60 & 3.38 & 3.25 & 3.85 & 64.01 \\
55 & 2.26 & 2.13 & 5.75 & 63.34 \\
50 & 1.98 & 1.87 & 5.56 & 63.41 \\
45 & 2.38 & 2.32 & 2.52 & 64.56 \\
40 & 1.28 & 1.25 & 2.34 & 64.62 \\
35 & 2.23 & 2.17 & 2.69 & 64.96 \\
30 & 1.15 & 1.10 & 4.35 & 63.88 \\
25 & 2.56 & 2.49 & 2.73 & 64.48 \\
20 & 1.92 & 1.87 & 2.60 & 64.53 \\
15 & 2.56 & 2.49 & 2.73 & 64.48 \\
10 & 0.99 & 0.93 & 6.06 & 63.22 \\
5 & 3.64 & 3.6 & 1.10 & 65.07 \\
0 & 2.00 & 1.96 & 2.00 & 64.74 \\
-5 & 1.46 & 1.42 & 2.74 & 64.48 \\
\hline
\end{tabular}

As can be seen in Table 10, the moisture content of rice leaves decreased to some extent as the temperature changed. With the increase of temperature, the moisture content itself tended to decrease, but the relative moisture content did not decrease by more than $6 \%$. According to the results of the moisture content of rice $(65.45 \%)$ before the test and the moisture content of rice leaves after each temperature effect, it could be seen that the temperature change had a certain effect on the moisture content of the rice itself. However, the overall impact was small, the relative reduction was not more than $6 \%$ and the maximum moisture content was not more than $3 \%$. Based the data of the tensile change test of two-point stretching of rice leaf with the change of moisture content, it could be known that when it was reduced from $60.71 \%$ (dried for $1 \mathrm{~min}$ ) to $26.39 \%$ (dried for $8 \mathrm{~min}$ ), the change of moisture content was $34.32 \%$. The tensile limit after drying for $1 \mathrm{~min}$ was about $32.63 \mathrm{~N}$, and the tensile performance after drying for 8 min was reduced to $26.53 \mathrm{~N}$, which was equivalent to $0.178 \mathrm{~N}$ of the amount of influence of $1 \%$ moisture content on its tensile performance. During the entire temperature change process, the moisture content had been reduced by up to about $3 \%$, so that the change in the tensile performance of the blade during the temperature change process was about $0.534 \mathrm{~N}$. Therefore, the main reason why the temperature changed the tensile properties of the blade was not that the temperature changed the moisture content of the blade itself. The main factor affecting the change of the tensile properties of the blades was the temperature itself.

\subsection{Relationship between the Grain and the Blade Crushing Force}

According to the results of the tensile properties of rice leaves at different temperatures, the tensile properties of rice leaves were weaker at lower temperatures and higher temperatures. The tensile properties of the leaves were best at $30-35{ }^{\circ} \mathrm{C}$. The overall change trend of the tensile properties of the blades at different temperatures was first to become stronger and then weaker. For comparison, the tensile properties of the blades at room temperature and $33^{\circ} \mathrm{C}$ were compared under two-point stretching and three-point stretching. The leaf sheath portion and the blade root data were integrated and are shown in Figure 15. 


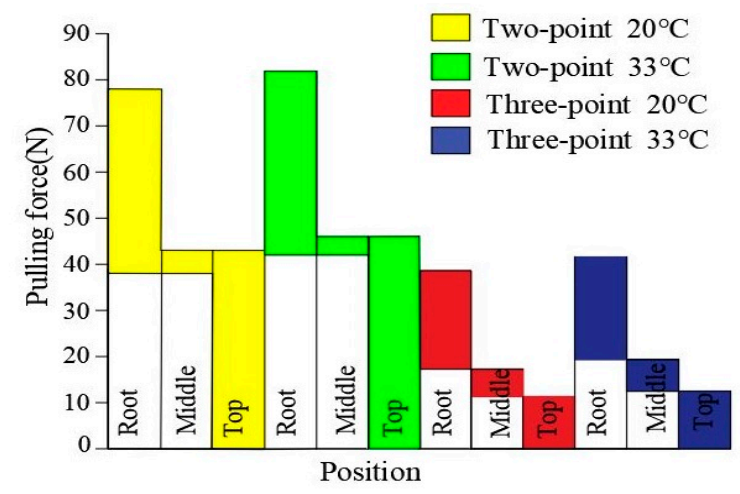

Figure 15. Comparison of tensile properties of root, middle and top of rice leaves.

As can be seen in Figure 15, the overall tensile strength of the blade at the three-point stretching was weaker than that at the two-point stretching and the overall appearance tended to gradually decrease from the root to the top. When it comes to the middle part of the blades, the tensile properties were not much different, and under the two-point tension, the fluctuation of the tensile force is more likely to occur; however, the variation range of the tensile limit is smaller. The overall tensile performance of the blade at $33^{\circ} \mathrm{C}$ was different from that at normal temperature. The mechanical properties of the blade are higher than normal at the root, middle or top of the blade and the overall mechanical performance improvement rate was $8-12 \%$. Considering the situation of rice in the threshing process, if the rice is heated before threshing, the mechanical properties of the leaves will be improved, and the breaking rate of the leaves can be reduced to a certain extent, thereby reducing the debris in the rice threshing process. Considering the grain threshing, its mechanical properties will also increase with the temperature. According to the test results, the tensile properties of individual grains under different moisture content ranged from $1.2 \mathrm{~N}$ to $2.2 \mathrm{~N}$. The force range of different parts of the blade, including the root of the blades (integrated with the sheath portion), the middle part, the top part and the tip part of the blades, were combined and analyzed.

The separation force of the grain was relatively small to the crushing force of the entire blade. It was known that the overall tensile strength of the blade was the highest in the range of $30-35^{\circ} \mathrm{C}$ of the temperature, and the separation force of the grain had little effect with temperature. The overall range was between $1.2 \mathrm{~N}$ and $2.2 \mathrm{~N}$. The crushing force of the blades and the separation force of the grain were mainly in the part from the top of the blade to the tip of the blades, and the tensile properties were also improved with the change of temperature. The test data of both the blade top at normal temperature and $33^{\circ} \mathrm{C}$ were analyzed and compared with the grain separation force. The results were shown in Figure 16.

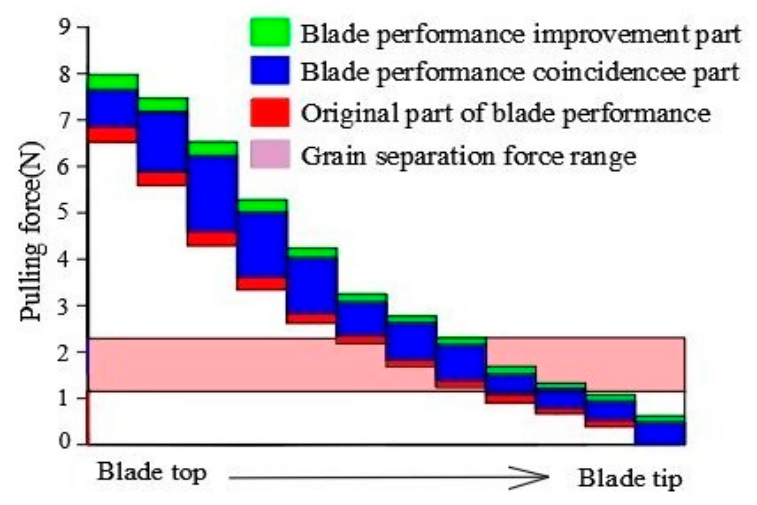

Figure 16. Comparison of tensile properties at the top of the blades. 
As can be seen in Figure 16, the overall tensile performance of blade top was increased by $8 \%$ to $12 \%$ with the temperature. Since the top of the blade itself had weak tensile properties, the base number was small; the improvement of tensile performance is not obvious relative to the root and middle of the blade. However, compared with the separation force of the grain, the overall performance of the blade was improved, and the overlap with the separation force of the grain had a certain decrease with the increase of temperature. It can be seen that if the temperature is properly increased during rice threshing, it will be beneficial to improve the overall mechanical properties of rice leaves, thereby reducing the leaf breaking rate to some extent, improving the separation efficiency of grain and leaves, and reducing the difficulty of subsequent grain separation and clearing.

\subsection{Tensile Properties of Multiple Blades at Normal Temperature}

Tensile properties of multiple blades at normal temperature were tested. The state of the blades after stretching was as shown in Figure 17a. The tensile performance curves of the leaves of different layers, as shown in Figure 17b. The relationship between the number of blade layers and the tensile limit is shown in Figure 17c.

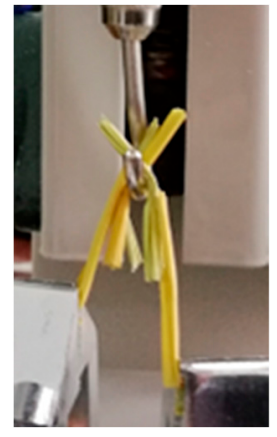

(a) five-layer blades broken

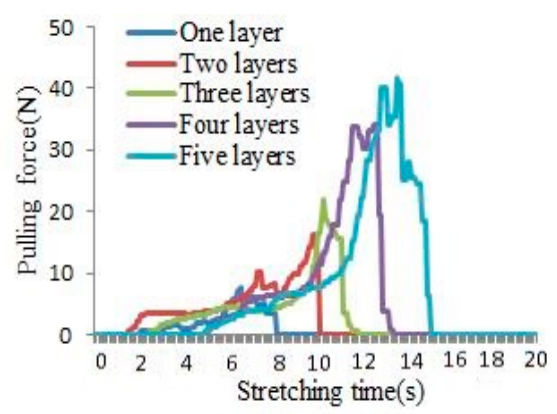

(b) Three-point tensile tension curves of multi-layer blades

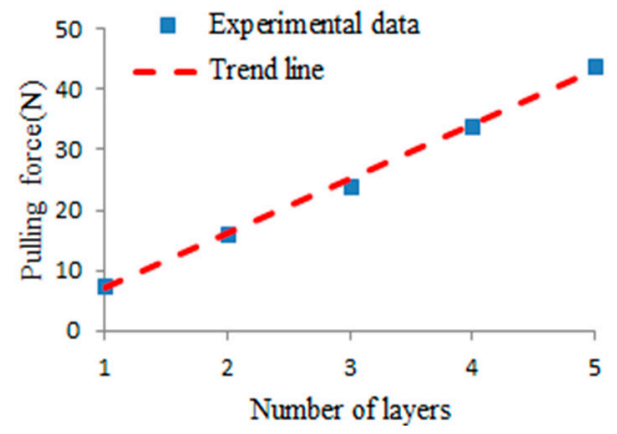

(c) Relationship between blade number and tensile limit

Figure 17. Tensile properties of multiple blades at normal temperature.

As can be seen in Figure 17b, the limit of the tensile force that a single-layer blade could withstand at room temperature was about $7.5 \mathrm{~N}$ (variance was 0.33 ). The limit of the tensile force that could be withstood by the two-layer blade at normal temperature was about $16 \mathrm{~N}$ (Variance was 0.21 ). The limit of the tensile force that could be withstood by the three-layer blade at normal temperature was about $23 \mathrm{~N}$ (variance was 0.44 ). The limit of the tensile force that could be withstood by the four-layer blade at normal temperature was about $34 \mathrm{~N}$ (variance was 0.44 ). The force that the five-layer blade could withstand was about $42 \mathrm{~N}$ (variance was 0.86 ). The corresponding regression line equations are different due to the tissue characteristics of the leaves and the influence of rice varieties. It can be seen that when the multi-layered blades in the threshing cylinder are overlapped, it is beneficial to improve the overall tensile performance and reduce the breaking rate of the blades. Through the change of temperature, the degree of improvement of the mechanical properties of the whole multi-layer blade can be multiplied, so that the overall performance of the blade during threshing can be improved to reduce the fracture rate.

\section{Conclusions}

There were significant differences in tensile strength between different parts of the blades. The tensile properties of the whole blades showed a trend of decreasing first, then rising and then decreasing from the sheath to the top of the blade. When the blade was laterally stressed, its lateral tensile limit was very small, so the blade is prone to lateral tear and lateral fracture during threshing. 
Through the tensile test of the blades at different temperatures and moisture, changes in moisture content had a greater effect on rice leaves performance, but temperature changes had a smaller effect on moisture content. With the gradual increase of temperature, the tensile performance of the blades increased first and then decreased. When the temperature changed, the tensile strength of the blade root changed the most, but the change rate of the overall tensile performance was basically $8 \sim 12 \%$. Whether it was two-point stretching or three-point stretching, the blade had the best tensile performance at $30 \sim 35^{\circ} \mathrm{C}$ and its tensile properties were weakened with increasing or decreasing temperature.

The tensile limit of the multi-layer blades was linear with the number of blade layers within the error range. When the multi-layer blades in the threshing cylinder were overlapped, it was beneficial to improve the overall tensile performance and reduce the breakage of the blades. Through the change of temperature, the degree of improvement of the mechanical properties of the whole multi-layered blade can be multiplied, thereby greatly reducing the overall breaking rate of the blade and reducing the difficulty of grain cleaning.

Author Contributions: Conceptualization, Z.T. and Y.L. (Yaoming Li); Methodology, Z.T., Y.L. (Yaoming Li), Y.L. (Yu Li) and B.Z.; Validation, Y.L. (Yu Li), B.Z. and M.W.; Formal Analysis, B.Z. and M.W.; Data Curation, Y.L. (Yu Li), B.Z. and Y.L. (Yu Li); Investigation, B.Z., M.W. and Y.L. (Yu Li); Writing-Original Draft Preparation, Y.L. (Yu Li), Z.T. and B.Z.; Writing-Review and Editing, Z.T. and Y.L. (Yu Li); Supervision, Z.T. and Y.L. (Yaoming Li). All authors have read and agreed to the published version of the manuscript.

Funding: This research work was supported by the Natural Science Foundation of Jiangsu Province (BK20170553), National Natural Science Foundation of China (51705212), Jiangsu Province "Six Talents Peak" High-level Talent Project (GDZB-085), Open Fund of Jiangsu Key Laboratory of Agricultural Equipment and Intelligent High Technology (JNZ201912) and a Project Funded by the Priority Academic Program Development of Jiangsu Higher Education Institutions (No. PAPD-2018-87).

Conflicts of Interest: The authors declare no conflict of interest.

\section{References}

1. Li, Y.; Hallerman, E.M.; Liu, Q.; Wu, K.; Peng, Y.; Wu, K.; Peng, Y. The development and status of Bt rice in China. Plant Biotechnol. J. 2016, 143, 839-848. [CrossRef] [PubMed]

2. Wang, W.; Sardans, J.; Wang, C. Straw Application Strategy to Optimize Nutrient Release in a Southeastern China Rice Cropland. Agronomy 2017, 7, 84. [CrossRef]

3. Prasad, R.; Shivay, Y.S.; Kumar, D. Current status, challenges, and opportunities in rice production. In Rice Production Worldwide; Springer: Cham, Switzerland, 2017; pp. 1-32.

4. Tang, Z.; Li, X.Y.; Chen, X.D.; Chen, Y. Design of Negative Pressure Spiral Feeding Device for Tangential and Longitudinal Axial Intersection of Combine Harvester. Adv. Mater. Sci. Eng. 2019, 2019, 1-12. [CrossRef]

5. Bilde, M.L.; Kristensen, M.B. Grain cleaning unit with cleaning airstream vented above grain pan for a combine harvester. U.S. Patent No. 9,867,336, 5 December 2014.

6. Zhang, Y.; Liu, Y.; Zhang, G. The Effects of Rice Straw and Biochar Applications on the Microbial Community in a Soil with a History of Continuous Tomato Planting History. Agronomy 2018, 8, 65. [CrossRef]

7. Zhong, T.; Li, X.X.; Liu, X.; Ren, H.; Zhang, B. Dynamic Balance Method for Grading the Chain Drive Double Threshing cylinder of a Combine Harvester. Appl. Sci. 2020, 10, 1026-1046.

8. Dorokhov, A.; Khamuev, V.; Lepeshkin, K. Modernization of grinding machines of grain cleaning machines. MATEC Web Conf. 2018, 224, 05009. [CrossRef]

9. Craessaerts, G.; Saeys, W.; Missotten, B. Identification of the cleaning process on combine harvesters, Part II: A fuzzy model for prediction of the sieve losses. Biosyst. Eng. 2010, 106, 97-102. [CrossRef]

10. Hiregoudar, S.; Udhaykumar, R. Artificial neural network for assessment of grain loss for paddy combine harvester a novel approach control. Comput. Inf. Syst. 2011, 140, 221-231.

11. Omid, M.; Lashgari, M.; Mobli, H. Design of fuzzy logic control system incorporating human expert knowledge for combine harvester. Expert Syst. Appl. 2010, 37, 7080-7085. [CrossRef]

12. Bart, L.; Thomas, A.; Engelbert, T. Simulation of grain-straw separation by Discrete Element Modeling with bendable straw particles. Comput. Electron. Agric. 2014, 101, 24-33.

13. Tom, L.; Bart, S.; Simon, V. A discrete element approach for modelling bendable crop stems. Comput. Electron. Agric. 2016, 124, 141-149. 
14. Li, W.X. Study on Physical Characteristics Test and Modeling Method of Rice Plants in Mature Period. Master's Thesis, Jilin University, Jilin, China, 2015.

15. Zhang, Z.; Wang, Z.K.; Cai, H.J. Estimation of evapotranspiration of winter wheat under deficent irrigation based on SIMDual_Kc model. J. Drain. Irrig. Mach. Eng. (JDIME) 2020, 38, 212-216.

16. Zhan, K.; Liu, X.J.; Ata-Ul-Karim, S.T.; Lu, J.S.; Krienke, B.; Li, S.Y.; Cao, Q.; Zhu, Y.; Cao, W.X.; Tian, Y.C. Development of Chlorophyll-Meter-Index-Based Dynamic Models for Evaluation of High-Yield Japonica Rice Production in Yangtze River Reaches. Agronomy 2019, 9, 1-17.

17. Tang, Z.; Li, Y.M.; Cheng, C. Development of multi-functional combine harvester with grain harvesting and straw baling. Span. J. Agric. Res. 2017, 15, e0202. [CrossRef]

18. Vinod, K.; Singh, B.S.; Dwivedi, R.P.; Mishra, A.K.; Shukla, J.T.; Pravin, K.; Upadhyay, K.S.; Kaushik, M.; Azad, S.P. Yields, Soil Health and Farm Profits under a Rice-Wheat System: Long-Term Effect of Fertilizers and Organic Manures Applied Alone and in Combination. Agronomy 2018, 8, 1-22.

19. Luo, T.; Ooi, E.T.; Chan, A.H.C. The combined scaled boundary finite-discrete element method: Grain breakage modelling in cohesion-less granular media. Comput. Geotech. 2017, 88, 199-221. [CrossRef]

20. Dai, F.; Song, X.; Zhao, W. Motion simulation and test on threshed grains in tapered threshing and transmission device for plot wheat breeding based on CFD-DEM. Int. J. Agric. Biol. Eng. 2019, 12, 66-73. [CrossRef]

21. Zhao, B.; Li, X.L.; Zhou, M.L.; Song, B.; Lei, E.; Li, Z. Analysis on the Status Quo and Influencing Factors of Grain Breakage Rate of Maize in Southwest China. Crop J. 2019, 19, 1-12.

22. Tang, Z.; Li, Y.M.; Zhao, Z. Structural and parameter design of transverse multi-cylinders device on rice agronomic characteristics. Span. J. Agric. Res. 2015, 13, e0216. [CrossRef]

23. Tang, Z.; Li, Y.M.; Xu, L.Z. Assessment of rice threshing and separation performance for just mature rice and over mature rice. Int. Agric. Eng. J. 2014, 23, 44-51.

24. Atis, I.; Konuskan, O.; Duru, M. Effect of harvesting time on yield, composition and forage quality of some forage sorghum cultivars. Int. J. Agric. Biol. 2012, 14, 879-886.

25. Zhang, L.; Hou, Y.Y.; Yang, B.Y.; Huang, D.P. Spatial-temporal characteristics and risk analysis of heat stress hazard of single-season rice across Yangtze River reaches. J. Nat. Disasters 2018, 27, 107-116.

26. Md-Sailm, N.S.; Gariepy, Y.; Raghavan, V. Hot air drying and microwave-assisted hot air drying of broccoli stalk slices (Brassica oleracea L. Var. Italica). J. Food Process. Preserv. 2017, 41, 1-9.

27. Gong, L.; Lin, K.; Wang, T.; Liu, C.L.; Yuan, Z.; Zhang, D.B.; Hong, J. Image-based on-panicle rice [oryza sativa 1.] grain counting with a prior edge wavelet correction model. Agronomy 2018, 8, 91. [CrossRef]

28. Wang, X.C.; Samo, N.; Li, L.M.; Wang, M.R.; Qadir, M.; Jiang, K.F.; Qin, J.; Rasul, F.; Yang, G.T.; Hu, Y.G. Root Distribution and Its Impacts on the Drought Tolerance Capacity of Hybrid Rice in the Sichuan Basin Area of China. Agronomy 2019, 9, 79. [CrossRef]

29. Yu, T.; Cui, N.B.; Zhang, Q.W. Applica-bility evaluation of daily reference crop evapotrans-piration models in Northwest China. J. Drain. Irrig. Mach. Eng. 2019, 37, 710-717.

30. Tang, Z.; Li, Y.M.; Xu, L.Z. Numerical simulation and test analysis of straw movement in threshing and separation unit. Int. Agric. Eng. J. 2014, 23, 35-42.

31. Tang, Z.; Li, Y.; Li, X.Y.; Xu, T.B. Structural damage modes for rice stalks undergoing threshing. Biosyst. Eng. 2019, 186, 323-336. [CrossRef]

(C) 2020 by the authors. Licensee MDPI, Basel, Switzerland. This article is an open access article distributed under the terms and conditions of the Creative Commons Attribution (CC BY) license (http://creativecommons.org/licenses/by/4.0/). 